\title{
MANAGEMENT OF PROCESSING TECHNOLOGY ON COMPUTERISED NUMERICALLY CONTROLLED CENTRES FROM PROGRAMMING AND SIMULATION TO OPERATION
}

\author{
Gheorghe Popovici * \\ University "Babeş-Bolyai” of Cluj-Napoca \\ UBB University Centre Reşiţa \\ 1-4, Traian Vuia Square, 320085 Reşiţa, Romania \\ * Corresponding author. E-mail: gheorghe.popovici@ubbcluj.ro
}

\begin{abstract}
The paper presents the peculiarities of the management of the processing technology on computerised numerically controlled centres, from the source code $G$ to the high level code. In order to do a skilled job, the programmer and / or the operator from the CNC centres will apply an operational management through which all the programming and operating instructions for making a part will reproduce the practical actions that a worker classically does. The paper presents the 10 stages of computer-aided processing. The applied research showed that it is more and more necessary to shorten the programming time to make a part by switching from $\mathrm{G}$ code to high level code as shown intuitively in the Sinu Train application. At the same time, the management of the processing technology on the CNC centres imposes more and more, through the new working conditions given by the pandemic, work from home (homework) and programming from home. Therefore, the online simulation of the program created is the new method of "cold testing" of a processing process. Finally, by operating on CNC centres, the compliance with the quality requirements given by the total quality management will always be pursued.
\end{abstract}

Keywords: operational management, quality management, CNC processing technology, computerised numerically controlled (CNC), programming, G code, high level code, simulation, operation.

\section{Premises}

We are today in the information society, having as conventional reference date August 12, 1981, when personal computers (PCs) have been launched on the market. Since then, three inventions have changed the world and influenced the lives of each generation: personal computers (1981), the Internet (1991) and smartphones (2007)..

Technology is the "unseen path" of a product from the state of raw material or semi-finished product to finished parts and assembly-product that offers buyers the desired benefits (advantages)

The notion of "technology" derives from the Greek words:

techno = craft, skill, art; and it means:

$\operatorname{logos}=$ word, thought, science,

"the science of doing something in a mastery manner" [2]., to work on a computer (IT), to make computer aided drawing (CAD), to process parts on numerically controlled machine tools (CAM)) etc.

The technology of mechanical processing by cutting is and will remain for a long time the main technological method of execution of the parts in the construction of machines.

Today, the trend is towards computer-controlled machine tools. In this case the programming of the machines is done by a computer in an integrated manufacturing system called CIM (Computer Integrated Manufacturing). It also went from classic drawing and drawing on the board, computer aided design and drawing on CAD (Computer Aided Design). For computer aided manufacturing, the concept is known as CAM (Computer Aided Manufacturing).

At the same time, there are new trends in research and technological development through the construction of intelligent machine tools (Smart Manufacturing Machines) and additive processing technologies (Additive Technology 3D).

\section{The Proposed Issues}

The management of the processing technology on computer numerically controlled centres is a new and modern one that is applied in a " factory of the future" is shown in figure 1 in a three-level pyramidal structure and systemically integrated by computer [3].

Level 1 - is the marketing and management at the level of TOP management.

Level 2 - of conception, design, programming at the level of MIDDLE management

Level 3 - is the execution of products or $L O W$ management, in which the number of operators is relatively low, the physical work being taken over by flexible manufacturing systems consisting of machine 
tools with computer numerical control and industrial robots, all being directed by a process computer.

What will be? The technological explosion of recent years has shown us that the future is being created at a particularly fast pace.

This is the question to which answers are sought through the synthesis of research on programming, simulation and operation on CNC centres.

\section{Core of the Issue}

The CNC centre operator is the person who knows how to make parts on machines with numerical control by computer and can perform the following activities:

- correctly read and interpret the technical drawings;

- $\quad$ adjust the entire MU-CNC technological system: machine, tools, devices and workpieces;

- program the processing phrases for the CNC command with the help of the computer and to simulate with the help of an application program the processing on virtual MUCNC;

- run on MUCNC the parts processing programs at the given shape and dimensions and with the required processing precision.
The know-how or skill of the operator involves three stages of preparation:

1. familiarization with the notions and specific technical language for operation on CNC machine tools;

2. skill in simulation and operation on MUCNC;

3. the ability to carry out programs on $M U C N C$.

Technological method (MT) shows the main way of carrying out a mechanical processing, distinguishing itself by laws and fundamental phenomena (in principle!).

Numerical control (CN) is a method of driving machine tools in which the operator provides control instructions, in sequences, one after the other, as a natural sequence of operations, phases and handling necessary to make a part.

Computer numerical control (CNC) is the modern method of programming a machine tool using a computer [1].

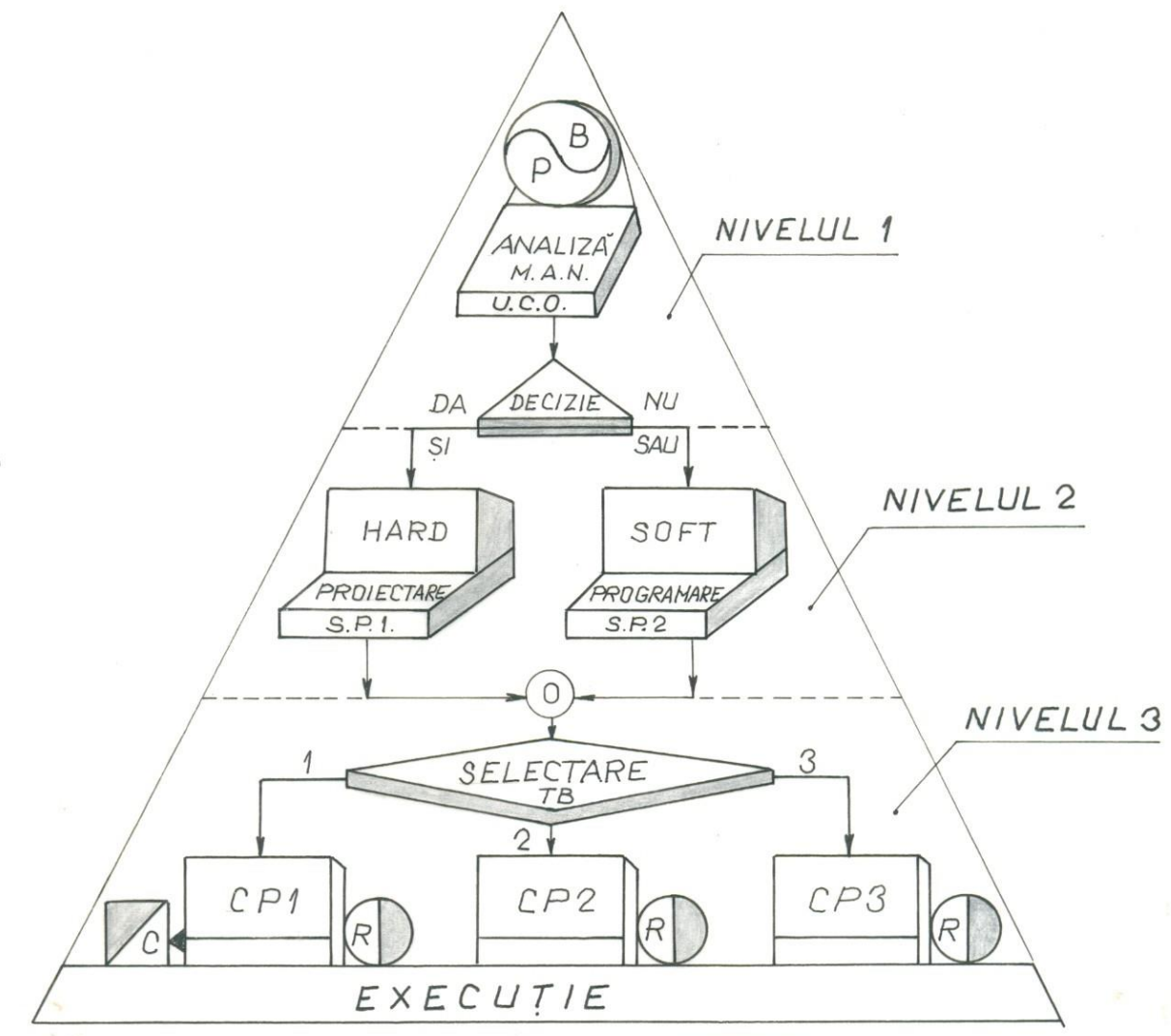

Fig. 1. A systemic view of CNC technology management

Legend: nivelul-level; analiză - analysis; decizie - decision; proiectare - design; programare - programming; selectare - selection; execuţie - execution 
A technological method is applied through technological processes.

The technological process (PT) is the concrete way of accomplishing a mechanical processing that observes the fundamental phenomena of the technological method, completing them, however, with its own phenomena and laws, corresponding to a certain execution technique (of practice!). The 4 basic methods of mechanical machining are: turning, drilling, milling, grinding.

So is the method of application of the computerised numerical control (CNC) on $\mathrm{CNC}$ machining centres, milling and grinding, which involves the practical completion of the 10 stages of work from processing on classic machine tools, but with certain specific features that the operator can logically identify only if it will be put in the worker's situation. The logical sequence of instructions is either written in $\mathbf{G}$ code, or in high-level language (code), is given by the order in which the actions of an operator would be done if he were to work manually on the machine tool, in order to make a given part according to its technical drawing.

The applied research was done with the help of the application Sinu Train for Sinumerik 840D/810D elaborated by Siemens company [4].

The working hypotheses were:

H1: Programming in high language is done in the logical sequence of writing the $\mathrm{G}$ code;

H2: Simulation of processing identically reproduces the actual processing;

H3: Operation is done in the working steps of the machining stages on CNC machine tools.

The standard part for processing is given in figure 2 :

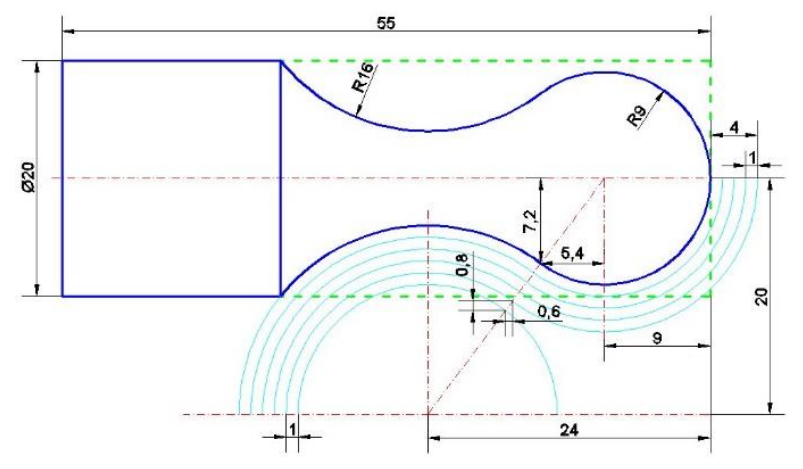

Fig. 2. Concave-convex step shaft

The turning operation is performed in two phases:

- Roughing, in several passes;

- Finishing, on contour.
The 10 stages of programming [2], simulation and operation on the CNC centres Turn 250 and Mill 155 were:

1. Reading the technical and programming characteristics from the CNC centre book;

2. Determining the origin of the machine $(M)$, of the part $(W)$, the tool reference point $(N)$ and of the $X Y Z$ axis system for motion reporting;

3. Establishing the working positions of the tools in the turret / tool magazine;

4. Completing the steps of commissioning the machine and identifying the control addresses of the machine tool;

5. Familiarization with the interface and keys of the numerical control by computer;

6. Choosing the dimensions of the semi-finished part and determining the contour points of the finished part;

7. Establishing the technological itinerary (operations, phases, handling and movements), identifying the necessary tools, and calculating the parameters of the cutting regimes;

8. Programming in $G$ code and / or in high level language (code) by writing the source code for making the workpiece;

9. Simulation of "cold" processing using the Sinu Train application;

10. Computer-assisted "hot" operation on CNC centres for manufacturing the part.

The first 7 steps are known by technologists. Therefore, only the final stages 8,9 and 10 are presented with the concrete mode of programming, simulation and operation for the practical realization of the piece.

\section{Step 8: Processing programme:}

\section{a) G code}

From the semi-finished product...

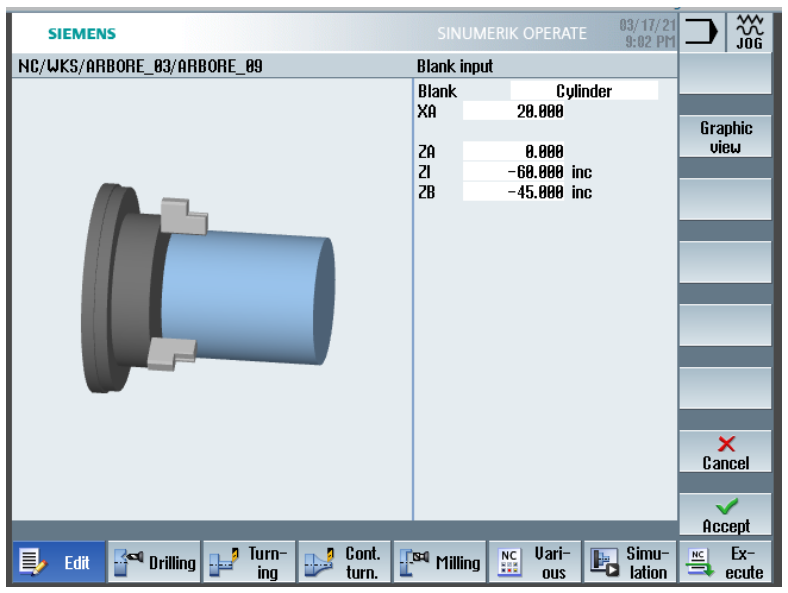




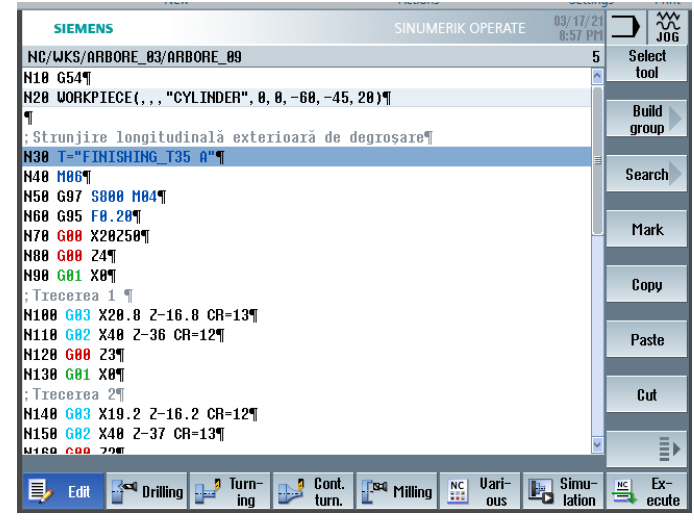

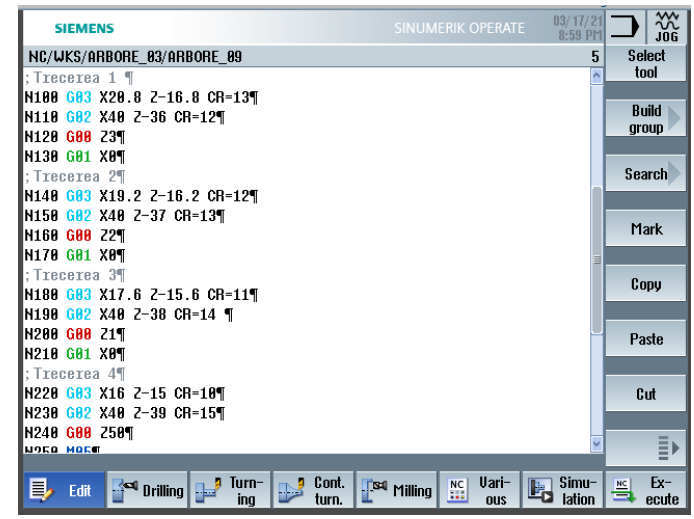

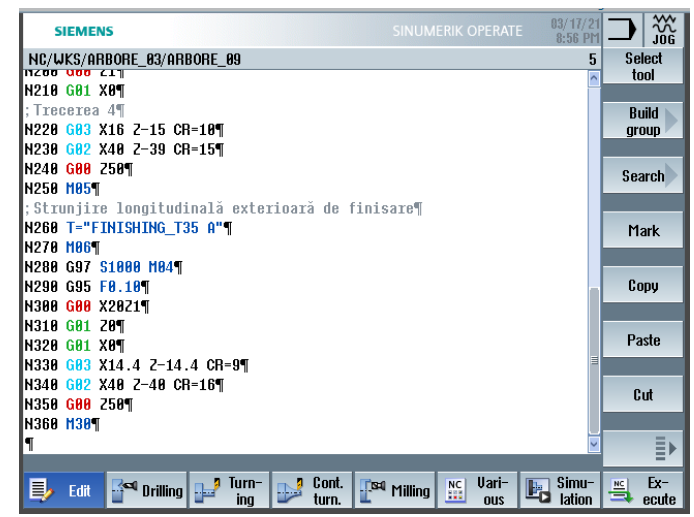

... to the finished part:

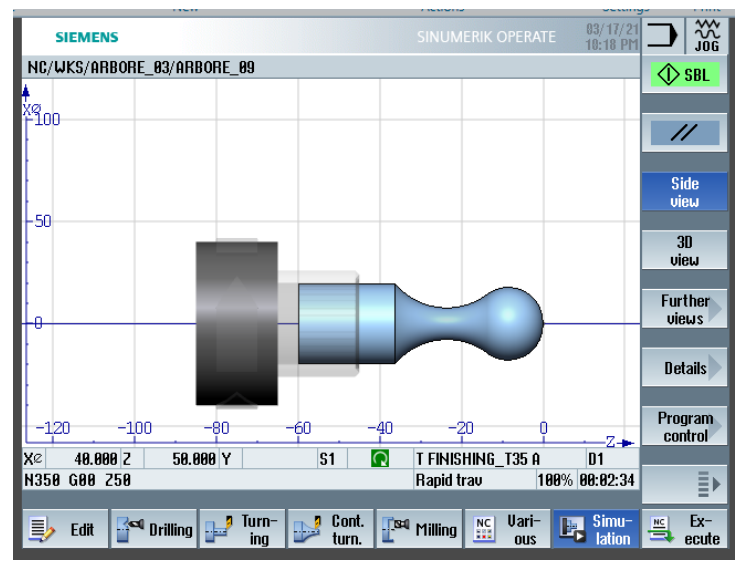

\section{b) High-level code}
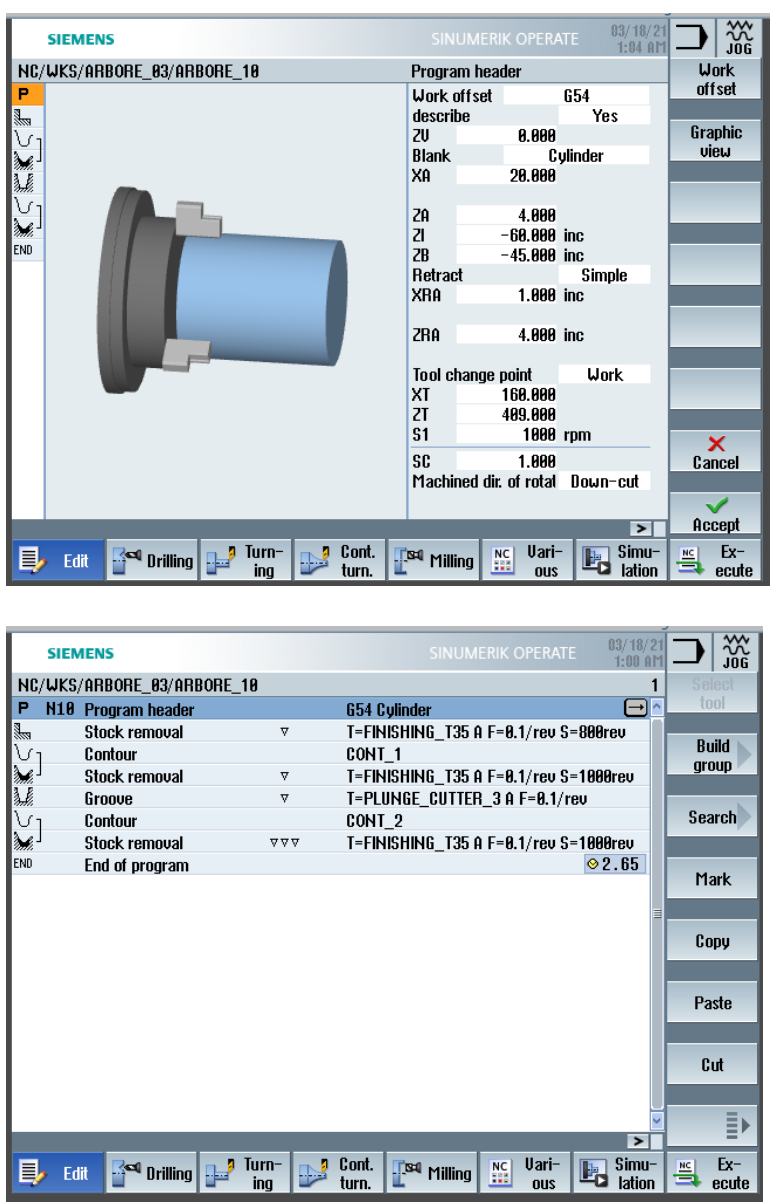

Step 9: Simulation one Sinu Train:

a) Roughing through several passes

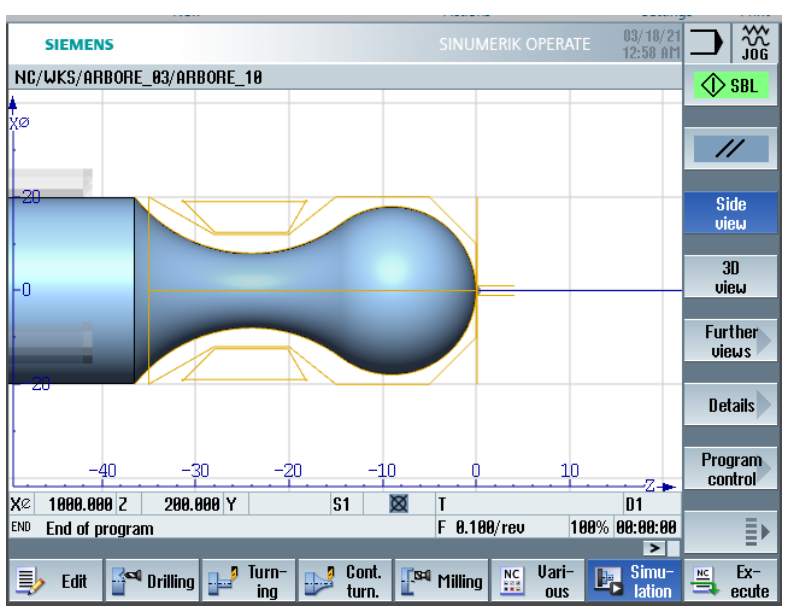



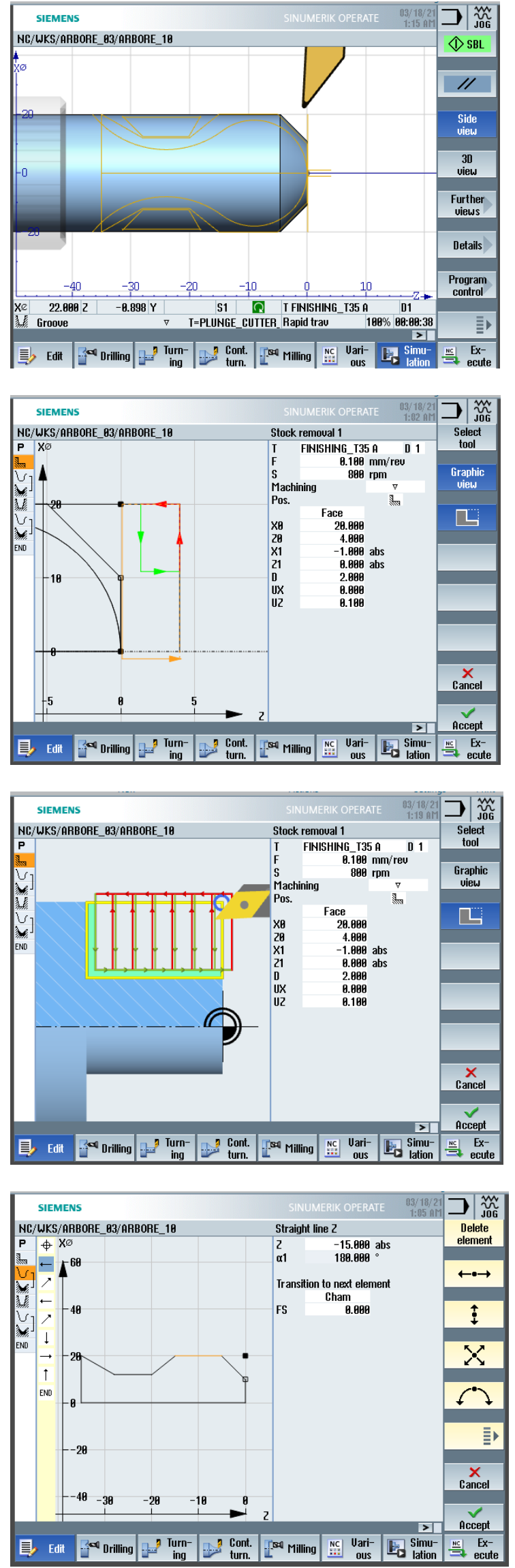
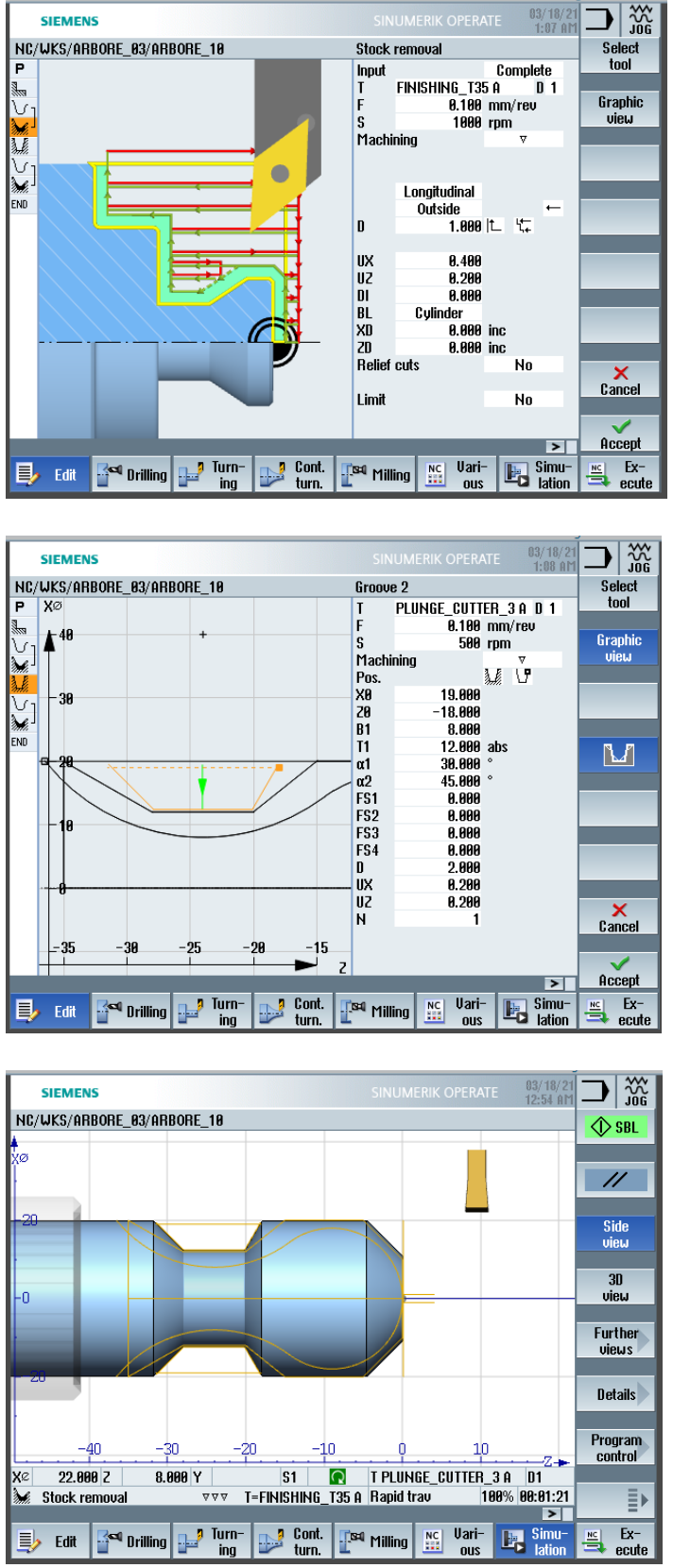

b) Contour finishing in a single pass

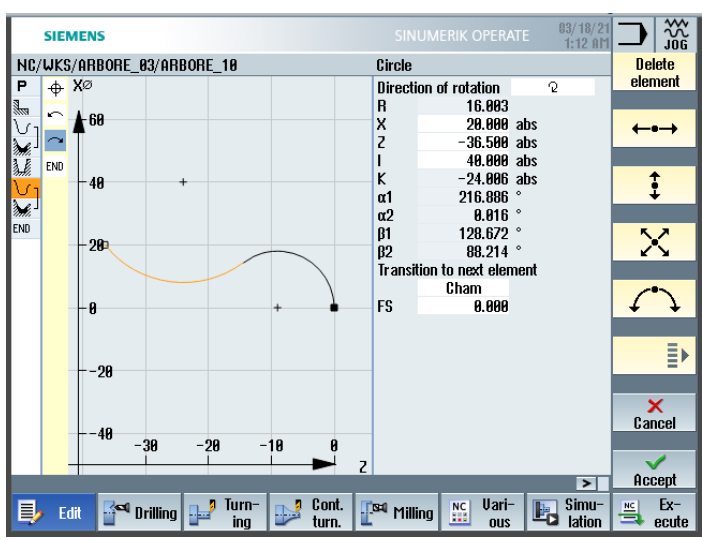



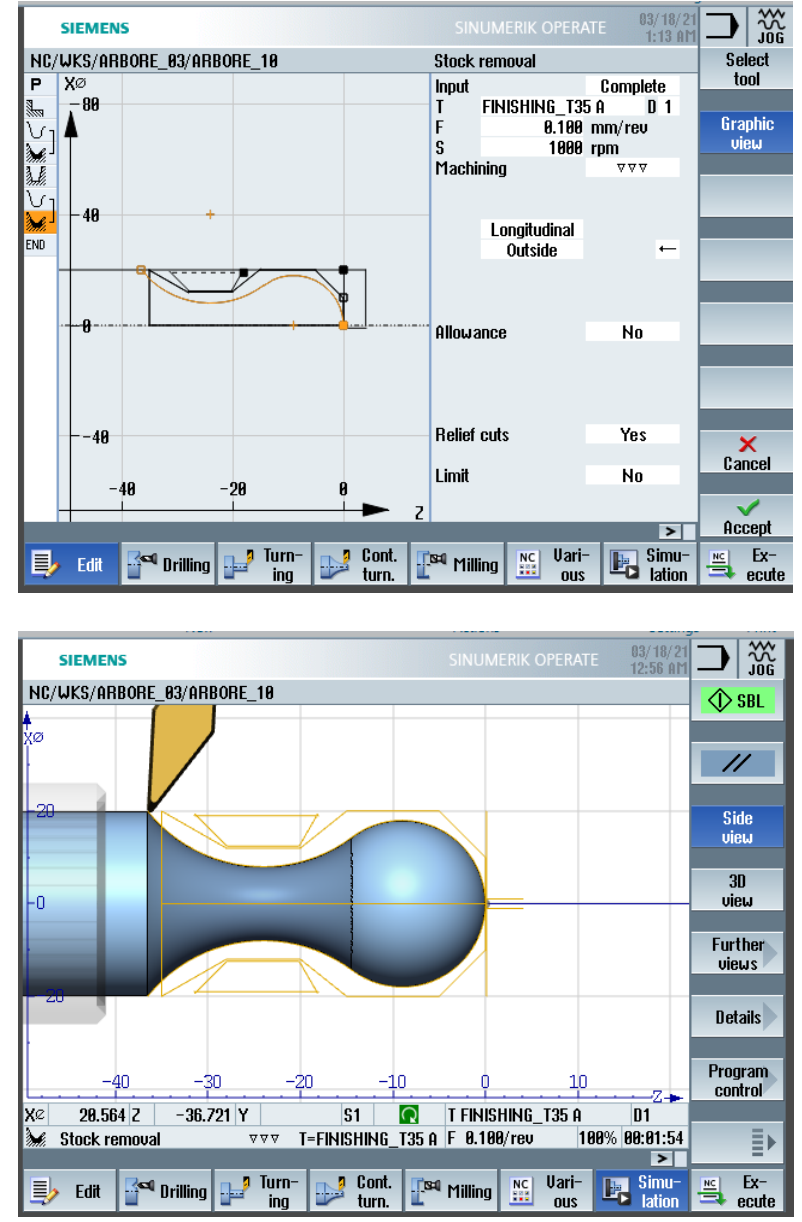

Step 10: CNC centre operation

From the point of view of quality management, each operator at MUCN aims to execute good quality parts through the following two requirements:

1. The quality of the parts comes first;

2. The responsibility for quality lies with the programmer and / or operator for each part.

The quality of a part manufactured on $\mathrm{CNC}$ centres is evaluated by the machining precision. The piece rendered on the execution drawing represents the ideal model (theoretically!). The part obtained after processing on $\mathrm{CNC}$ centres is the real one. The degree of proximity between the executed part and the drawing part constitutes the processing precision.
The operational management on the CNC centres Turn 250 and Mill 155 by going through the work steps confirmed the three hypotheses of the applied research.

\section{Conclusions:}

From the applied research regarding the management of the processing technology on $\mathrm{CNC}$ machining centres, the following conclusions can be deduced:

1. It is increasingly necessary to shorten the programming time for manufacturing a piece by switching from $\mathrm{G}$ code to high level code as shown intuitively in the Sinu Train application;

2. The management of the processing technology on the CNC centres imposes more and more, through the new working conditions given by the pandemic, work from home (home-work) and programming at home. Therefore, the online simulation of the realized program is the new method of "cold testing";

3. Operation on CNC centres, in order to comply with quality requirements, requires the logical reading of programming instructions (blocks) as actions (operations, phases, handling) of the operator who would work manually on the machine tool, to make a part.

\section{References}

[1] Bartenschlanger J., et al.: Fachkunde Metal", Verlag Europa-Lehrmittel, Germany, 2015, pag. 564608.

[2] Popovici, Gh.: "Study on production management in programming for computer numerical control machines", Robotica \& Management, vol. 19, no. 2, 2014, pag. 16-20.

[3] Rampersad, H.: "Total performance scorecard", Management Consulting. Didactic and Pedagogical Publishing House, Bucharest, 2005, pag. 35-53.

[4] *** Application programme Sinu Train https://new.siemens.com/global/en/markets/machinebui lding/machine-tools/cnc4you/sinutrain

\section{BIOGRAPHICAL DATA}

Popovici Gheorghe (born in 1958) graduated from the Faculty of Mechanics of the "Politehnica" University of Timişoara, he was awarded a PhD degree in engineering in 1995 by UP Timișoara and a $\mathrm{PhD}$ degree in marketing granted in 2007 by the West University of Timișoara. Technicalscientific publications: 25 books, 3 patents and 125 scientific papers published in the fields of Engineering and management of technological systems, Marketing, Tourism Marketing and Online Marketing. For the works he received the "Ion Ionescu de la Brad" award of the Romanian Academy (2019). 